Journal of Engineering and Applied Sciences 14 (Special Issue 2): 5479-5482, 2019

ISSN: 1816-949X

(C) Medwell Journals, 2019

\title{
Study of the Effect of Conducting Polymer on the Optical Properties of Laser Dyes
}

\author{
Ban Salam Abdalhadi, Lazem Hassan Aboud and Nizar Salim Shnan \\ Department of Laser Physics, Science Collage for Women, University of Babylon, \\ Alhila, Babel, Iraq, physicstbanoo@gmail.com
}

\begin{abstract}
In this study has been studied the effect of the conducting polymer (Polyaniline) on the optical properties of laser dyes. Studied three different concentrations $\left(1^{*} 10^{-3}, 5^{*} 10^{-4}, 1^{*} 10^{-4}\right)$ of dissolved fluorescein sodium dye in distilled water. Absorption and fluorescence spectra, absorption and refraction coefficients, Quantum efficiency $\left(\mathrm{Q}_{\mathrm{FM}}\right)$ and fluorescence lifetime $\left(\tau_{\mathrm{f}}\right)$ values were studied for these three concentrations. After that, $(3 \mathrm{~mL})$ of polyanylene was added to the dye solution and the polymer effect was studied on the optical properties of the dye. The results showed a decrease in absorbance values with a shift towards the short wavelengths (blue shift) of the absorption spectra of the dye solution and thus, a decrease in the values of refractive and absorption coefficients, a decrease in the fluorescence intensity and the quantum efficiency and an increase in the fluorescence lifetime of with a shift towards the short wavelengths (Blue shift) due to the effect of the molecular electrical band (HOMO and LUMO) of the conducting polymer on the electrical energy levels of dye molecule.
\end{abstract}

Key words: $\mathrm{HOMO}$ and LUMO, spectra, absorption, refraction coefficients, quantum efficiency, electrical energy

\section{INTRODUCTION}

Polymers are large molecules made up of small interconnected units called monomer units. Polymers are sometimes crystalline crystals and sometimes amorphous or a mixture of the two. The majority of polymers lack good electrical conductivity, so, their applications were limited to their mechanical properties and chemical properties. Their electrical uses were limited to electrical insulators (Dyson, 1986; Sentukia, 1985; Mot and Pfisten, 1982) because they had good electrical insulation properties. In 1977, one of these polymers is the PolyAcetylene (PA) which can be transformed into a conductive polymer by treating it with appropriate impurities in the oxidation and reduction method (Chiang et al., 1997). The emergence of different types of ring and aromatic polymers that follow the same behavior $\mathrm{Mg}$ new conductive polymers called anguish (conducting polymer (Tourillon and Garnier, 1982). This kind of polymers are rapidly gaining a lot of attention. The main motive behind this concern is the use of these materials in the field of industrial applications, especially, electronic ones because they are characterized by good properties in terms of cost and ease of manufacture and the need for low deposit temperatures and wide area (Kaneto et al., 1991). In addition, the use of

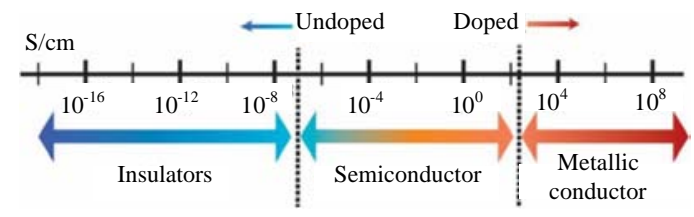

Fig. 1: The general conductivity range of conducting Fig. 5. The general conductivity range of Conducting Polymers ((CPs))

electronic circuits integrated with non-microwaves is much more important than the use of inorganic semiconductor technology (Skotheim, 1986). The use of these polymers In the early stages of the development of these polymers, some problems have hampered this development. These problems are not soluble in any of the solvents (Insoluble) or fusion (infusible) (Isolato et al., 1993; Burroughes et al., 1988; Wang et al., 1990). In recent years, soluble conductive polymers have been obtained by adding some chemicals to the monomer unit (Fig. 1).

\section{MATERIALS AND METHODS}

Preparation of the samples: A concentration of $1 \times 10-3$ M 1 fluorescein sodium dye solution in watter solvent was

Corresponding Author: Ban Salam Abdalhadi, Department of Laser Physics, Science Collage for Women, University of Babylon, Alhila, Babel, Iraq, physicstbanoo@gmail.com 
prepared. The powder was weighting using an electronic balance type (BL 210 S) Germany having a sensitivity 4 digits:

$$
\mathrm{W}=\frac{\mathrm{M}_{\mathrm{W}} \times \mathrm{V}^{1} \mathrm{xC}}{1000}
$$

Where:

$\mathrm{W}=$ Weight of the dissolved dye $(\mathrm{g})$

$\mathrm{M}_{\mathrm{w}}=$ Molecular weight of the dye $(\mathrm{g} / \mathrm{mol})$

$\mathrm{V}=$ The Volume of the solvent $(\mathrm{mL})$

$\mathrm{C}=$ The dye Concentration $(\mathrm{mol} / \mathrm{L})$

Different concentrations were provided according to the following Eq. 2:

$$
\mathrm{C}_{1} \mathrm{~V}_{1}=\mathrm{C}_{2} \mathrm{~V}_{2}
$$

Where:

$\mathrm{C}_{1}=$ Primary Concentration

$\mathrm{C}_{2}=$ New Concentration

$\mathrm{V}_{1}=$ The Volume before dilution

$\mathrm{V}_{2}=$ The Volume after dilution

Add a percentage of the polymer solution (Polyaniline+Water) to the dye solution and move the mixture well to obtain a homogeneous mixture of dye and polymer.

\section{RESULTS AND DISCUSSION}

Absorption spectra: For the first case, UV-VIS absorption spectra were obtained for fluorescein sodium dye solution at different concentrations $\left(1 \times 10^{-4}, 5 \times 10^{-4}\right.$ and $1 \times 10^{-3}$ ) Ml. The behavior of Fluorescein sodium dye solution was shown in Fig. 2.

From Fig. 2, the results showed that the absorption peaks of fluorescein sodium dye solution are $(490,490$, $487 \mathrm{~nm}$ at $\left(1 \times 10^{-3}, 5 \times 10^{-4}\right.$ and $\left.1 \times 10^{-4} \mathrm{MI}\right)$, respectively, absorbance increased with increasing concentration This increase was overall obtained due to the increasing number of molecules per volume unit at high concentration, this in turn lead to change in energy levels result in effect of vibration field on molecules and the spectral range covered $(418-514 \mathrm{~nm})$. For the second case, the absorption spectra of Fluorescein sodium dye at the concentrations $\left(1 \times 10^{-3}, 5 \times 10^{-4}\right.$ and $\left.1 \times 10^{-4} \mathrm{MI}\right)$ after doped by PANI polymer were shown in Fig. 3 .

From Fig. 3, absorption peaks are $(448,439$ and 436) $\mathrm{nm}$ at different concentrations $\left(1 \times 10^{-3}, 5 \times 10^{-4}\right.$ and $\left.1 \times 10^{-4}\right)$ $\mathrm{Ml}$, respectively, also the absorbance was increas with increasing concentrations for the same reason. The absorbance was lower than fluorescein sodium dye solution because of the electric field of the polymer, also, the spectral range was wider than fluorescein sodium dye solutions.

Transmission spectra: The transmission spectra of the fluorescein sodium dye at the three cases were analyzed

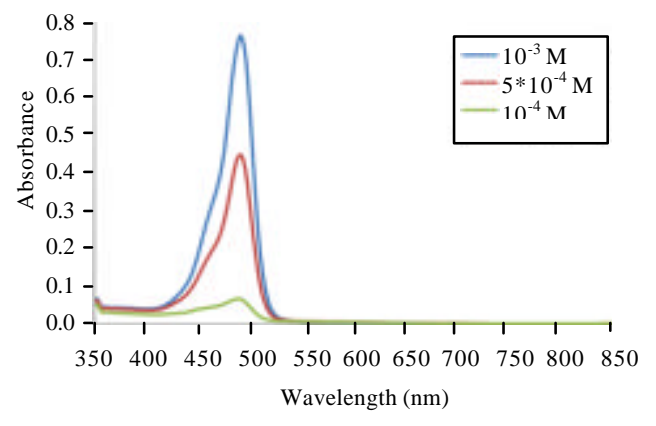

Fig. 2: Absorption spectra for fluorescein sodium dye in water

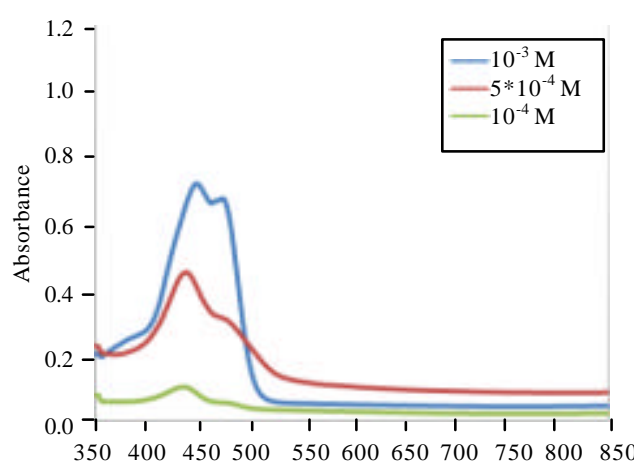

Wavelength $(\mathrm{nm})$

Fig. 3: UV-VIS absorption spectrum of the fluorescein sodium dye doped PANI polymer

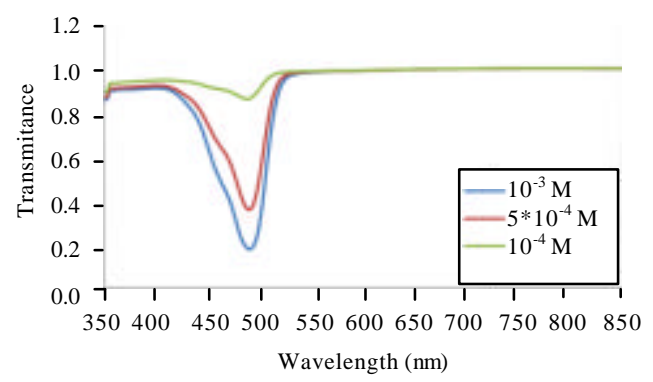

Fig. 4: UV-Vis transmittance spectrum of the fluorescein sodium dye solution at different concentrations

using UV-Vis spectrophotometer. For the first case transmission spectra were obtained for fluorescein sodium dye solution at different concentrations $\left(1 \times 10^{-3}, 5 \times 10^{-4}\right.$ and $1 \times 10^{-4} \mathrm{MI}$ ). The behavior was shown in Fig. 4 .

The transmission spectra of fluorescein sodium dye at concentrations $\left(1 \times 10^{-3}, 5 \times 10^{-4}\right.$ and $\left.1 \times 10^{-4} \mathrm{MI}\right)$ after doped PANI polymer were shown in Fig. 5.

Transmission values in this case are less than fluorescein sodium dye solutions and decreased with increasing concentration. 


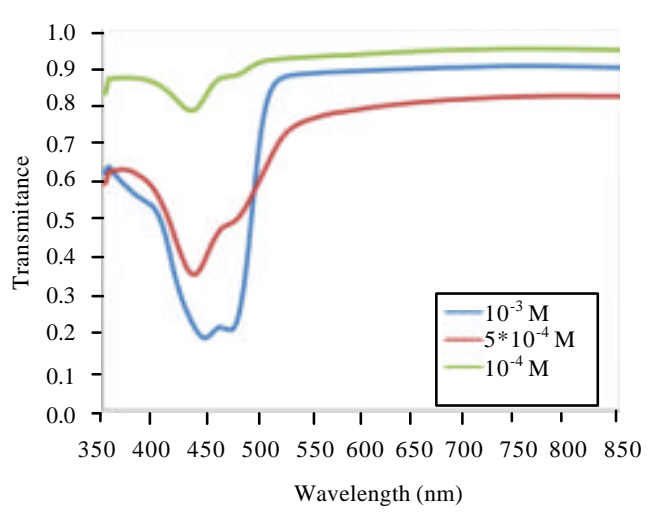

Fig. 5: UV-Vis transmittance spectrum of the fluorescein sodium dye doped PANI polymer

\section{Linear absorption coefficient and linear refractive index} results: After obtaining the results the absorption spectra can calculation linear optical properties (absorption coefficients $\left(\alpha_{0}\right)$ and refraction $\left.\left(\mathrm{n}_{0}\right)\right)$ enter the following mathematical relationships in the computer program (Excel):

$$
\begin{gathered}
\alpha_{\mathrm{o}}=2.303 \mathrm{~A} / \mathrm{d} \\
\mathrm{n}_{0}=\left(\frac{4 \mathrm{R}}{(1-\mathrm{R})^{2}}-\mathrm{K}^{2}\right)^{\frac{1}{2}}-I\left(\frac{\mathrm{R}+1}{\mathrm{R}-1}\right)
\end{gathered}
$$

Where:

$\mathrm{A}=$ The absorbance

$\mathrm{d}=$ The optical path length

$\mathrm{R}=$ The reflectivity

$\mathrm{K}=$ Decay factor

In Table 1 and 2 , it is noticed that linear refractive index for second case in solution doped PANI is lower than linear refractive index at the first case in fluorescein sodium dye which means the velociety of light inside fluorescein sodium dye doped PANI is decresed because of Polyaniline molecular.

Fluorescence spectra: Figure 6 shows fluorescence spectra of the first case : fluorescein sodium dye solution at different concentrations $\left(1 \times 10^{-3}, 5 \times 10^{-4}\right.$ and $1 \times 10^{-4}$ MI).

Figure 6 indicated emission peaks $(523,568,565 \mathrm{~nm})$ for $\left(1 \times 10^{-3}, 5 \times 10^{-4}, 1 \times 10^{-4} \mathrm{MI}\right)$, respectively, also viewed higher intensity with increasing concentration .

For the second case, the fluorescence spectra of fluorescein sodium dye at concentrations $\left(1 \times 10^{-3}, 5 \times 10^{-4}\right.$ and $\left.1 \times 10^{-4} \mathrm{MI}\right)$ after doped PANI polymer were shown in Fig. 7.

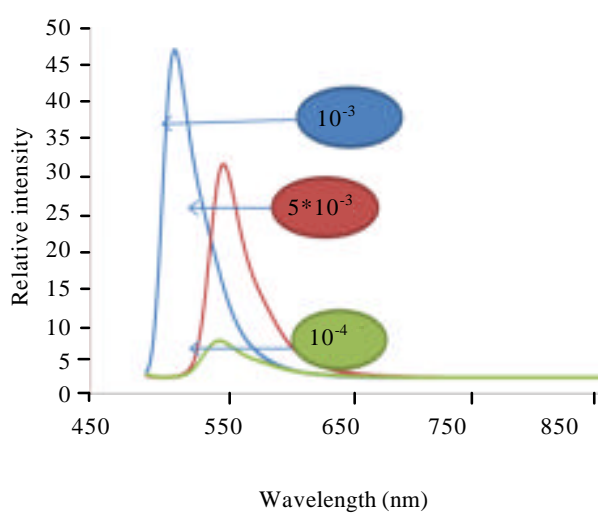

Fig. 6: Fluorescence spectrum of fluorescein sodium dye solution at different concentrations $\left(1 \times 10^{-3}, 5 \times 10^{-4}\right.$, $\left.1 \times 10^{-4} \mathrm{MI}\right)$

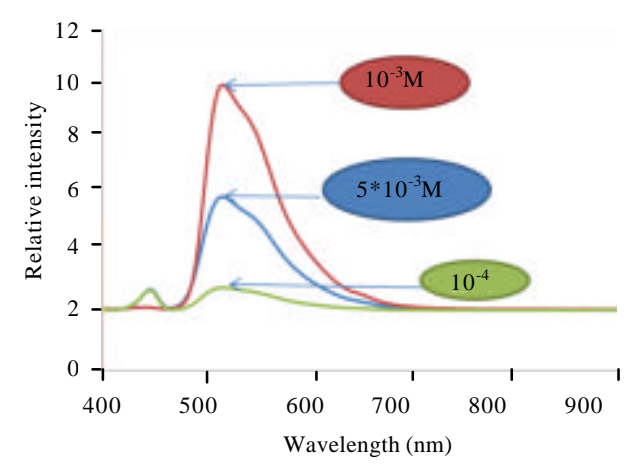

Fig. 7: Fluorescence spectrum of fluorescein sodium dye doped pani at different concentrations

Table 1: Linear absorption coefficient and linear refractive index fluorescein sodium dye solution at different concentrations

\begin{tabular}{llc}
\multicolumn{3}{c}{ sodium dye solution at different concentrations } \\
\hline $\mathrm{C}(\mathrm{mL})$ & $\alpha_{0}\left(\mathrm{~cm}^{-1}\right)$ & $\mathrm{n}_{0}$ \\
\hline $10^{-3} \times 1$ & 1.753389 & 2.690751 \\
$10^{4} \times 5$ & 1.030899 & 1.334019 \\
$10^{4} \times 1$ & 1.008904 & 1.288770 \\
\hline
\end{tabular}

Table 2: Linear absorption coefficient and linear refractive index of Table 2: Linear absorption coefficient and
fluorescein sodium dye doped PANI

\begin{tabular}{llc}
\hline $\mathrm{C}(\mathrm{mL})$ & $\alpha_{0}\left(\mathrm{~cm}^{-1}\right)$ & $\mathrm{n}_{0}$ \\
\hline $10^{3} \times 1$ & 1.655019 & 1.413990 \\
$10^{4} \times 5$ & 1.029982 & 2.091298 \\
$10^{4} \times 1$ & 0.237192 & 1.514580 \\
\hline
\end{tabular}

Figure 7 indicated emission peaks $(517,516,515 \mathrm{~nm})$ for $\left(1 \times 10^{-3}, 5 \times 10^{-4}, 1 \times 10^{-4} \mathrm{MI}\right)$, respectively, also viewed higher intensity with increasing concentration.

As shown in Fig. 6 and 7, the intensity of fluorescence after addition of the PANI decreases with the shift towards short wavelengths. Also, there is an expansion in the spectral width. This is due to the fact that the energy levels of the polymer interfere with the energy levels of the dye giving an emission spectrum that differs from the pure dye emission spectrum. 
Table 3: Quantum efficiency and life time for fluorescein sodium dye

\begin{tabular}{llc}
\hline $\mathrm{C}(\mathrm{mL})$ & $\mathrm{t}_{f}(\mathrm{n} \mathrm{sec})$ & $\mathrm{Q}_{\mathrm{f}}$ \\
\hline $1 \times 10^{-3}$ & 0.061 & 0.63 \\
$5 \times 10^{4}$ & 0.034 & 0.70 \\
$1 \times 10^{-4}$ & 0.012 & 0.76 \\
\hline
\end{tabular}

Table 4: Quantum efficiency and life time of fluorescein sodium dye doped PANI polymer

\begin{tabular}{llc}
\hline $\mathrm{C}(\mathrm{mL})$ & $\mathrm{t}_{\mathrm{f}}(\mathrm{n} \mathrm{sec})$ & $\mathrm{Q}_{\mathrm{f}}$ \\
\hline $10^{-3} \times 1$ & 0.069 & 0.59 \\
$10^{4} \times 5$ & 0.046 & 0.70 \\
$10^{4} \times 1$ & 0.021 & 0.81 \\
\hline
\end{tabular}

Fluorescence lifetimes $\left(\tau_{f}\right)$ and Quantum yield fluorescence $\left(Q_{f}\right)$ were calculated using the relationships:

$$
\begin{gathered}
(\mathrm{F}=(\mathrm{a} \times(\mathrm{fRB}) / \mathrm{aRB} \\
\phi_{\mathrm{F}}=\frac{\int \mathrm{F}\left(\mathrm{v}^{\prime}\right) \mathrm{dv^{ \prime }}}{\int \varepsilon\left(\mathrm{v}^{\prime}\right) \mathrm{dv^{ \prime }}}
\end{gathered}
$$

After calculation of the area under the curve of the absorption and fluorescence using the software (GEUP 6) and the results as shown in Table 3 and 4.

We observe from Table 3 and 4 that the fluorescence lifetimes $\left(\tau_{f}\right)$ increases after the addition of the polymer for all the concentrations. Quantum efficiency is reduced in all concentrations except for concentration $1^{*} 10^{-4}$.

\section{CONCLUSION}

The following remarks are concluded during the present research: a decrease in the concentration of the dye solution leads to the shift of the top absorption spectra towards the short wavelengths (blue shift). The change in the concentration of the dye solution has a significant impact on the linear optical properties (the refractive and linear absorption coefficients) of the absorption spectra where the concentration increases with the refractive and absorption parameters. The lifetime $\left(\tau_{f}\right)$ increases with increasing concentration. The Quantum yeild $\left(Q_{f}\right)$ of fluorescence decreases with the concentration of the solution. Addition of the polymer to the dye solution results in a decrease in absorbance values with a blue shift of the absorption spectra and the fluorescence. The lifetime $\left(\tau_{f}\right)$ increases when the polymer is added to the dye solution. Decrease in Quantum yeild $\left(Q_{f}\right)$ of fluorescence after the addition of polymer except the concentration $1^{*} 10^{-4} \mathrm{~mL}$.

\section{REFERENCES}

Burroughes, J.H., C.A. Jones and R.H. Friend, 1988. New semiconductor device physics in polymer diodes and transistors. Nat., 335: 137-141.

Chiang, C.K., C.R. Fincher, Y.W. Park, A.J. Heeger and H. Shirakawa et al., 1997. Electrical conductivity in doped polyacetylene. Phys. Rev. Lett., 39: 1098-1101.

Dyson, R.W., 1986. Specialty Polymers. Champan and Hall, New York, USA.,.

Isotalo, H., M. Ahlskog, H. Stubb, J. Laakso and T. Karna et al., 1993. Stability of processed poly (3-Octylthiophene) and its blends. Synth. Met., 57: 3581-3586.

Kaneto, K., T. Asano and W. Takashima, 1991. Memory device using a conducting polymer and solid polymer electrolyte. Japanese J. Appl. Phys., 30: L215-L217.

Mot, J. and G. Pfisten, 1982. Electronic Properties of Polymers. John Wiley and Sons Inc., Hoboken, New Jersey, USA., Pages: 296.

Skotheim, T.A., 1986. Handbook of Conducting Polymers. Vol. 2, Marcel Dekker, ýNew York., USA., ISBN:9780824774547, Pages: 1417.

Tourillon, G. and F. Garnier, 1982. New electrochemically generated organic conducting polymers. J. Electroanal. Chem. Interfacial Electrochem., 135: 173178.

Wang, S., H. Takahashi, K. Yoshino, K. Tanaka and T. Yamabe, 1990. Dependence of Poly(3-alkylthiophene) film properties on electrochemical polymerization conditions and alkyl chain length. Japanese J. Appl. Phys., 29: 772-775. 